\title{
Percepção moral dos profissionais de supermercados no Brasil*
}

\author{
Renato Almeida dos Santos ${ }^{1}$ \\ Arnoldo José de Hoyos Guevara ${ }^{2}$ \\ Maria Cristina Sanches Amorim ${ }^{3}$ \\ Pontifícia Universidade Católica de São Paulo (PUC/SP)
}

Fraude e corrupção são fenômenos sistêmicos que provocam rupturas no tecido social e vultosos prejuízos às organizações governamentais e privadas, e em última instância, ao cidadão. Na raiz da fraude e corrupção está a percepção moral do indivíduo, sua compreensão da natureza ética em escolhas profissionais. O objetivo da pesquisa é avaliar a percepção moral de profissionais do varejo no Brasil. Utilizou-se análise estatística social e descritiva de dados secundários cedidos formalmente pela empresa ICTS Global. A amostra é não probabilística por conveniência, realizada entre os anos de 2004 e 2011, com 11.850 profissionais de empresas privadas situadas no Brasil. Os dados obtidos com a pesquisa mostram que há diferenças significativas quanto à percepção moral no setor varejista, comparativamente aos demais setores da economia brasileira, no sentido de ser este menos suscetível a suborno; e, ainda, observa-se certa diferença nas áreas do próprio setor quanto às percepções sobre suborno.

Palavras-chave: Fraude - ComplianceÉtica nas organizações - Governança
Fraud and corruption are systemic phenomena that cause ruptures in the social fabric and huge losses for private and public organizations and ultimately for the citizen. At the root of fraud and corruption is the moral perception of the individual, that is, the understanding of the ethical nature and their consequences in his/her conduct. The aim of our research is to evaluate the moral perception of professionals from the retail segment in Brazil. We used social and descriptive statistical analyses of secondary data granted by company ICTS Global. The sample is nonprobabilistic by convenience, and the data was collected between 2004 and 2011, with 11.850 employees from Brazilian private enterprises. The data show that there are relevant differences in relation to moral perception in the retail segment when compared with other sectors of the Brazilian economy as this sector isn't more susceptible to bribery; moreover it can be observed certain differences related to the perception of bribery in this particular sector.

Keywords: Fraud - Compliance - Ethics in enterprises - Governance

\footnotetext{
"Moral perception of professionals from the retail segment in Brazil

${ }^{1}$ Artigo apresentado no III Congresso Latino-Americano de Varejo, Fundação Getúlio Vargas, São Paulo, 21 e 22 de outubro de 2010. Doutorando em Administração pela Pontifícia Universidade Católica de São Paulo. Endereço para correspondências: Rua Ministro Godói, 969, $4^{\circ}$ andar, bloco A, sala 4E04, Perdizes, São Paulo, SP, 05015-000 (santos.renatoa@gmail.com).

2 Professor-Doutor do Programa de Administração da PUC de São Paulo.

${ }^{3}$ Professora-Doutora do Programa de Administração da PUC de São Paulo.
} 
Introdução

$\mathrm{O}$ combate à fraude e corrupção deve ser encarado como uma necessidade que se justifica por si, como providência de natureza ética e moral, essas por sua vez, valores e regras fundamentais à vida coletiva. No campo econômicofinanceiro, medir o quanto a sociedade ou as organizações perdem com a corrupção é tarefa espinhosa. Apesar da dificuldade, o impacto econômico da corrupção é reconhecido como significativo, devemos insistir em quantificá-lo, pois a mensuração pode sensibilizar a sociedade para a magnitude do problema (ABRAMO, 2005). Fraude e corrupção atingem o desenvolvimento econômico provocando ineficiência e incentivos errados para investimentos, desestimulando a população na busca pelo bem comum, gerando altos custos sociais e políticos (SPECK, 2000).

A mensuração de problemas desta natureza é complexa e controversa (BREI, 1996), ainda assim, os dados disponíveis permitem compreender a magnitude do fenômeno. Segundo a Transparência Internacional (2011), o Brasil ocupou a posição $73^{\mathrm{a}}$ na colocação no ranking de corrupção percebida (entre 183 países), atrás de Porto Rico $\left(36^{\circ}\right)$, Malásia $\left(57^{\circ}\right)$ e Kuwait $\left(68^{\circ}\right)$. A média do CPI (Corruption Perceptions Index) em 2009 foi de 4,03, superior ao índice brasileiro de 3,80, indicando que a corrupção percebida no Brasil ainda é bastante elevada, mesmo com melhora quando comparada ao índice de 2010. De acordo com simulações produzidas pela Federação das Indústrias de São Paulo - FIESP (2010), o custo médio anual da corrupção no Brasil é de pelo menos $1,38 \%$ do PIB (a soma de toda a riqueza produzida no país), algo como $\mathrm{R} \$ 41,5$ bilhões que saem dos cofres públicos ou sequer chegam ao seu destino. Os recursos desviados por atos de corrupção, se aplicados na educação, elevariam em $47 \%$ a quantidade de alunos matriculados na rede pública do ensino básico, representando cerca de 51 milhões de jovens e crianças beneficiadas. O total de domicílios com acesso a esgoto poderia aumentar em 103,8\%. Na saúde, a quantidade de leitos para internação poderia crescer $89 \%$ : mais 327.012 leitos; 2,9 milhões de famílias poderiam ter suas necessidades de habitação atendidas na construção de casas populares.

A fraude não é exclusiva quando do uso de bens públicos, assola todas as organizações, inclusive as privadas, afetando-as nos resultados financeiros. A quarta edição da pesquisa "A fraude no Brasil", realizada pela KPMG com base em questionário enviado para mais de mil das maiores empresas do país, concluiu que $70 \%$ dos entrevistados sofreram fraude em sua companhia nos últimos dois anos. Além disso, $50 \%$ das empresas acreditam que a fraude no Brasil poderá aumentar nos próximos dois anos. A maior parte das perdas (77\%) é inferior a R \$ 1 milhão, índice abaixo da versão anterior da pesquisa, realizada em 2004, quando apresentou $83 \%$. Porém, o percentual de perdas na faixa entre R\$ 1 milhão e R\$ 5 milhões cresceu dois pontos percentuais para 14\% (KPMG, 2009). 


\section{Percepção moral dos profissionais de supermercados no Brasil}

R.A. dos Santos, A.J. de H. Guevara \& M.C.S. Amorim

Association of Certified Fraud Examiners (ACFE) realizou um estudo baseado na compilação de 1.843 casos de fraudes ocorridos em empresas norte-americanas investigados entre 2008 e 2009. Análises foram realizadas em diversos segmentos, dentre eles, varejo, bancos e serviços financeiros, governo, educação, transporte, etc. Para cada segmento foi mensurada a média de perda por fraude cometida. No segmento varejo, a média de perda (por caso) foi de US\$85.000, o segmento representou 6,6\% da amostragem, totalizando 119 casos (ACFE, 2010).

$\mathrm{Na}$ busca pela transparência e de condutas éticas adequadas, as organizações precisam conhecer melhor o problema e desenvolver pessoas capazes de perceber e agir de acordo com as regras organizacionais. Na raiz da conduta corrupta ou, da conduta ética, está a percepção moral, isto é, a compreensão do indivíduo sobre o significado de suas atitudes à luz da moral vigente e das regras organizacionais (SANTOS et al., 2010).

$\mathrm{O}$ varejo possui um elevado giro nas compras e na quantidade de fornecedores, o que poderia configurar facilidades maiores ao suborno, quando comparado aos outros setores da economia. Interessa-nos investigar essa situação. O debate sobre fraude e corrupção é multifacetado, para discuti-lo no setor varejista, propomos como foco de análise o dilema ético presente no suborno. Cientes das dificuldades teóricas e práticas quanto à definição e mensuração da fraude e corrupção (BREI, 1996), ainda assim, procuramos avançar no entendimento das causas do problema, entre elas, a percepção moral e a pressão situacional.

Os dados disponíveis para nossa pesquisa possibilitaram análise quantitativa como estratégia de primeira abordagem ao fenômeno da percepção moral relativa a suborno dos profissionais do segmento varejista, conforme descrito no item metodologia. Pesquisas qualitativas futuras poderão aprofundar o entendimento das pressões situacionais e sua influência nas decisões relativas a dilemas éticos.

No campo das pressões situacionais está o componente social e econômico subjacente ao fenômeno da fraude e corrupção. Apresentar o histórico e a complexidade das relações de causalidade entre corrupção e contexto econômico-social foge ao escopo do presente artigo. Ainda assim, na literatura próxima aos estudos sobre organizações, valem as referências a Sennett (2002), Durkheim (2003) e Sen (1999).

Richard Sennett (2002) na obra "A corrosão do caráter - conseqüências pessoais do trabalho no novo capitalismo" apresenta estudo sociológico sobre as formas do "novo" capitalismo para o controle do trabalho e o caráter. Artigo recente de Costa e Wood Jr.(2012) sobre as fraudes corporativas recupera, entre outras, as contribuições de Durkheim (2003) para apontar as conseqüências da desintegração das normas sociais sobre as condutas individuais. 
UMANAS

Amartya Sen (1999), prêmio Nobel de economia, também explorou o tema em "Sobre ética e economia".

\section{Suborno, corrupção e fraude}

Na literatura examinada não há definição pacífica sobre suborno, muitas vezes não o distinguindo da corrupção e da fraude. A legislação brasileira, por exemplo, caracteriza-o como uma forma de corromper um agente público. Em outros países, o fato cometido pelo servidor público é denominado "corrupção" (o mesmo que corrupção passiva na legislação brasileira); o praticado pelo particular (o mesmo que corrupção ativa na legislação brasileira), "suborno" (DAMÁSIO DE JESUS, 2010). Assumiremos para escopo deste trabalho a seguinte definição:

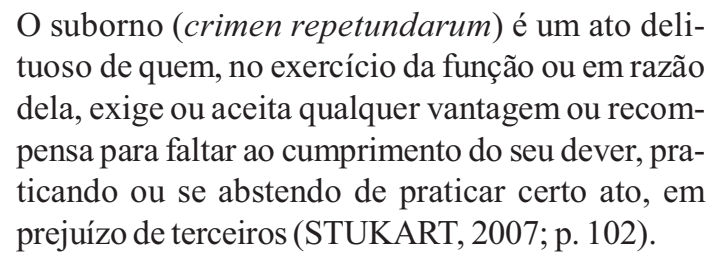

Ao considerarmos que suborno é o ato de induzir alguém, mediante quaisquer recompensas, a não cumprir o seu dever, não podemos restringir a ação ao agente público, seja na sua forma ativa ou passiva. O suborno constitui conduta que atenta contra o princípio de lealdade nas relações, sejam privadas ou públicas - o nexo comum entre ambos os tipos de suborno é o descumprimento dos princípios éticos. E quando tais princípios são ofendidos, são corrompidos na origem: por isso o suborno é uma forma de corrupção (não a única, mas uma delas).

O Grupo de Trabalho do Pacto Empresarial pela Integridade contra a Corrupção não limita a definição de corrupção a atos ilegais, considerando muito difícil definir todas as situações classificáveis como corrupção. Classifica, mesmo que não exaustivamente, um rol dos atos de corrupção estabelecidos pelos mais diferentes países: pagamento de suborno no âmbito do país ou em transações comerciais internacionais; tráfico de influência; abuso de poder; enriquecimento ilícito; suborno no setor privado; "lavagem" de dinheiro e obstrução da justiça. A corrupção é:

Relação social (de caráter pessoal, extramercado e ilegal) que se estabelece entre dois agentes ou dois grupos de agentes (corruptos e corruptores), 


\title{
Percepção moral dos profissionais de supermercados no Brasil R.A. dos Santos, A.J. de H. Guevara \& M.C.S. Amorim
}

\begin{abstract}
cujo objetivo é a transferência de renda dentro da sociedade ou do fundo público para a realização de fins estritamente privados. Tal relação envolve a troca de favores entre os grupos de agentes e geralmente a remuneração dos corruptos ocorre com o uso de propina ou de qualquer tipo de pay-off, prêmio ou recompensa (CGU, 2009; p. 60).
\end{abstract}

De acordo com a classificação The Fraud Tree apresentada pela Association of Certified Fraud Examiners a fraude está categorizada em "corrupção", "apropriação indevida de recursos" e "demonstrações fraudulentas", sendo que $86,3 \%$ delas foram classificadas como "apropriação indevida de recursos", a "corrupção" representava 32,8\% dessas perdas e as demais em "demonstrações fraudulentas" (ACFE, 2010). Assim, fraude é gênero e corrupção, espécie. O suborno, por sua vez, pode transitar entre as três categorias de fraudes, e até mesmo concomitantemente entre elas, pela sua característica sistêmica, conforme veremos no decorrer desse trabalho.

Para a compreensão do fenômeno suborno de maneira abrangente é necessário a compreensão da fraude, definida:

\section{[...] Toda forma de engenhosidade humana a que um indivíduo utiliza para obter vantagem em rela- ção a outro ao fazer insinuações falsas ou ao su- primir a verdade. Isso inclui a surpresa, o engano, a esperteza ou dissimulação e qualquer forma in- justa por meio da qual alguém é enganado (WE- LLS, 2002; p. 2201).}

A definição de Wells (2002) destaca os elementos da fraude e não seus autores. O primeiro elemento, a "engenhosidade humana", aponta para o fenômeno da super-socialização, isso é, para obter êxito, o fraudador necessariamente precisará contar com certo grau de confiança ou falha de controle da vítima, ou ainda, a não observância de cuidados com processos e planejamento que considerassem a má fé. O segundo elemento, a obtenção de vantagem, compreende o dolo em um ato de fraude, sem o qual, haveria apenas erro por imprudência, negligência ou imperícia. A vantagem em pauta pode assumir várias formas (busca pelo poder, dinheiro, status social, sexual, etc.). O último elemento - supressão da verdade - trata da dissimulação ou omissão de fatos como fator preponderante, sem o qual não existiria vítima. A vítima pode ser um indivíduo, grupo ou organização, pública, privada ou do terceiro setor. 
UMANAS

\section{Triângulo da fraude}

$\mathrm{Na}$ tentativa de explicar as causas da fraude, Cressey (1953) propõe a expressão "triângulo da fraude" para qualificar a existência da fraude: racionalização, necessidade/pressão e oportunidade. O primeiro vértice (racionalização) trata do discernimento do indivíduo sobre o certo e errado, a percepção moral diante de dilemas éticos. $\mathrm{O}$ fraudador precisa racionalizar seus atos, justificar, para si e para outros que determinada ação não é errada ou, caso o seja, amenizar a situação flexibilizando a ética. No segundo vértice (necessidade/pressão) o autor aborda a necessidade ou pressão a qual o indivíduo esteja submetido, considerando o contexto do potencial fraudador. $\mathrm{O}$ último vértice (oportunidade) é a percepção da oportunidade para a obtenção do objeto da fraude, é a idéia que o potencial fraudador faz do quão vulnerável o objeto está e os meios necessários à execução da fraude.

Cressey (1953) propõe seis tipos de problemas interligados que propiciam o cometimento de fraude: endividamento, problemas pessoais, reversão dos negócios, isolamento físico, busca por status financeiro e relacionamento entre empregador-empregado. Na década de 80 , partindo do triângulo da fraude, Albrecht e colaboradores (1984) desenvolvem a "escala da fraude", sugerindo que em uma escala entre baixo e alto é possível mensurar a fraude levando em consideração três indicadores: pressão situacional, oportunidade de cometimento e percepção moral. No primeiro indicador, são observados os problemas imediatos do indivíduo, por exemplo, perdas financeiras. O segundo indicador contempla as falhas de controles internos que possibilitem o cometimento de fraude gerada por um empregado, no caso de uma fraude corporativa. O último indicador é a integridade pessoal, refere-se ao comportamento ético que o indivíduo tende a adotar em diversas situações. Para os autores, esse indicador é o mais complexo de se analisar, pois decorre do desenvolvimento moral.

Para o entendimento da vértice do triângulo da fraude, denominado "oportunidade de cometimento" consideramos os fenômenos de sub e super-socialização. O primeiro prega a inevitabilidade dos controles formais, sem os quais, as oportunidades de fraude promoveriam condutas ilícitas; o segundo trata do peso das relações pessoais na ocorrência ou ausência de atos fraudulentos, defendendo o quanto a confiança poderia substituir parte dos dispositivos de controle. Ambas orientações têm limites no controle e prevenção de fraudes: controles absolutos e infalíveis não existem, se existissem, poderiam ser mais onerosos que o objeto controlado; apostar demasiadamente na construção de relações de confiança desconsidera a complexidade do comportamento humano, resultando em recomendações simplórias (GRANOVETTER, 2006). 


\section{Percepção moral dos profissionais de supermercados no Brasil}

R.A. dos Santos, A.J. de H. Guevara \& M.C.S. Amorim

Para definir se determinado ato humano é ético ou não, é necessário considerar três critérios: o objeto, a finalidade e as circunstâncias (GÓMEZ PÉREZ, 1983). O primeiro critério é a natureza do objeto; o segundo, o objetivo de determinado ato; o terceiro é das circunstâncias, dos diversos fatores ou modificações nas decisões éticas do indivíduo (ARRUDA et al., 2001). É esse terceiro critério que o vértice "pressão situacional" do triângulo busca contemplar. No mesmo estudo que gerou a teoria da "escala da fraude" Albrecht e colaboradores (1984) pesquisaram as motivações de 212 fraudes registradas nos primeiros anos da década de 80 , resultando em 9 categorias: 1) viver acima dos padrões de renda; 2) incontrolável desejo de ganhos pessoais; 3 ) possuir dívidas; 4) relação próxima com o cliente; 5) sentir que pagar não faz parte de suas responsabilidades; 6) ter uma atitude de desafio aos procedimentos e paradigmas; 7) ter prazer ao quebrar sistemas; 8) gostar do jogo ou apostas; e 9) famílias desestruturadas ou pressão do cônjuge. As categorias não são exaustivas quando consideramos as necessidades que podem acometer o ser humano, porém, oferecem um caminho para o desenho de instrumentos de controle.

Na classificação da percepção moral Heidenheimer (1970) propõe três categorias: 1) corrupção preta - quando a lei e a norma social coincidem, ou seja, há sinergia entre as percepções da sociedade com a norma jurídica vigente; 2) corrupção branca - ocorre quando a lei tipifica determinado ato como crime, mas há uma tolerância ou mesmo discordância dessa tipificação pela sociedade; e, 3) corrupção cinza - quando não há consenso de que determinado ato é ou não considerado como execrável.

A axiologia, estudo dos valores morais e éticos, indica que um ato antiético pode se materializar sob diversas formas (ROMANO, 2004). Não é diferente com o suborno, uma vez que ele encontra as mais variadas facetas, sendo a mais comum delas o objetivo patrimonial direto, no qual o corruptor faz um pagamento monetário ao subornado, por exemplo, quando um vendedor de uma empresa fornecedora paga dinheiro ao comprador da organização adquirente para que esta influencie ou tome a decisão de comprar. Sua quantificação pode ser fixada tendo por base um percentual do valor da transação fraudulenta, ou em um valor aleatório. O seu pagamento tende a ser vinculado ao ato da concretização da transação, uma vez que é a única garantia de sucesso nessa fraude que o subornador possui e, baseada nessa garantia, alguns subornadores executam o pagamento de forma gradativa quando o objeto da corrupção também é progressivo.

Seria um grande erro acreditar que o suborno sempre será configurado na forma de dinheiro, como se a força propulsora da vida dos indivíduos se reduzisse ao desejo por dinheiro. Philip Slater (1980) afirma: "a idéia de que todo mundo quer dinheiro é propaganda difundida por ricos viciados para conseguirem sentir-se melhor consigo mesmo sendo como são" (apud KOHN, 1998; p. 142). 
Diversas pesquisas sobre motivação do indivíduo nas organizações indicam que a busca pela recompensa em espécie não é o único elemento em pauta (KOHN, 1998), ainda que as dificuldades financeiras possam proporcionar uma situação mais vulnerável frente a uma oferta de suborno.

O suborno apresenta maior grau de sofisticação quando em sua forma indireta. Além do capital econômico (renda, salários, imóveis), Pierre Bourdieu (2007) apresenta outras formas de acúmulo de capital: cultural, social e simbólico (SÁ, 2010). O capital cultural é o acumulo de saberes e conhecimentos reconhecidos por diplomas e títulos. Indústrias farmacêuticas podem adotar como prática patrocinar congressos científicos a profissionais da área de saúde, denominando esses patrocínios como incentivo à pesquisa e ao estudo. Não por outro motivo, no Brasil, a Agência Nacional de Vigilância Sanitária - ANVISA - proíbe às indústrias essas práticas. A ANVISA entende que as facilidades oferecidas aos profissionais de saúde pelas indústrias podem apresentar conflito de interesses quando esses profissionais são influenciados a adotar determinados medicamentos ou outros produtos em suas prescrições, comprometendo o objetivo da pesquisa.

O capital social (as relações sociais que podem ser convertidas em recursos) pode ser apresentado na forma de redes de relacionamento. Uma das formas de acumular capital social por meio de suborno dá-se pelo nepotismo, privilegiar parentes para ocupar cargos. $\mathrm{O}$ termo tem origem na administração eclesiástica, quando os sobrinhos (em latim "nepo") do papa, pela condição do parentesco, possuíam cargos e regalias na igreja católica. O nepotismo não se dá apenas em cargos públicos, mas no setor privado também, quando em razão de determinada vantagem o fornecedor promete ao comprador um emprego na sua organização. Ainda em busca do capital social, o agente passivo do suborno pode concretizar determinada operação comercial com intuito de projetar-se socialmente para o mercado, mesmo que isso resulte em um prejuízo à organização.

O capital simbólico é adquirido por prestígio, permitindo identificar os agentes no espaço social. Ingressos para shows, boates, festas, eventos esportivos; almoços e jantares em restaurantes caros são maneiras de presentear um potencial cliente agregando a ele capital simbólico, provocando-lhe a sensação de ser reconhecido como importante no processo decisório que envolve a organização ofertante. Esse capital pode ser acumulado de forma antiética quando o potencial fornecedor de um produto oferece uma visita técnica ao comprador, arcando com os custos de viagem, hospedagem, desvirtuando a proposta original do desenvolvimento profissional. Premiações do tipo "o melhor comprador" também é uma forma de se exaltar o ato de compra.

Em síntese, o suborno pode ser configurado nas mais variadas formas, como prêmios, viagens, incentivos a estudos, facilitação em redes de relacionamentos, serviços, etc.; pode ser uma vantagem social, acadêmica, política, 


\section{Percepção moral dos profissionais de supermercados no Brasil}

R.A. dos Santos, A.J. de H. Guevara \& M.C.S. Amorim

sexual ou qualquer outra. E por ser de difícil mensuração, é difícil detectar e combater, daí sua sofisticação. Para efeito desse trabalho, utilizaremos o termo "presentes" para nos referirmos ao suborno extra patrimonial.

O subornado pode buscar uma justificativa de ordem compensatória das privações às quais está submetido (KOHN, 1998). Essas privações podem ser externas à organização a qual está vinculado, como por exemplo, endividamento financeiro, necessidade de subsídio para tratamento de saúde (seu ou de pessoa próxima), custeio de um vício (drogas, jogos, prostituição, etc). As privações internas à organização estão associadas à percepção individual de injustiça e/ou má fé por parte da organização (ROSE-ACKERMAN, 2002). É desalentador observar que as possíveis motivações apresentadas até agora não possuem limites.

Um dos principais freios à propina é a restrição moral, ou seja, aceitar (ou oferecer) ou não favorecimentos é uma atitude resultante da percepção e escolha ética. A reflexão moral depende, por sua vez, tanto da formação do empregado quanto do ambiente. O fenômeno do suborno é sistêmico, pode ser iniciado por agentes externos à empresa e acaba por envolver agentes internos, porém continua um problema inerente à gestão da empresa (GRANOVETTER, 1985). A organização pode influenciar a reflexão moral individual, auxiliando a decisão quando dilemas éticos surgirem. Isso é possível com a expressão e conscientização da conduta normativa das questões éticas e morais socializadas por meio dos valores e crenças organizacionais (BORINI \& GRISI, 2009).

\section{Metodologia e descrição dos dados}

Nossa análise é exploratória (COLLIS \& HUSSEY, 2005) e objetiva aprofundar o conhecimento de fatores que influenciam a decisão do indivíduo no cometimento de fraude na organização, avaliando a percepção moral de profissionais do varejo no Brasil. Utilizamos análise estatística social e descritiva (BABBIE, 2003) de dados secundários cedidos formalmente pela ICTS Global, empresa internacional de consultoria especializada na redução de riscos ao patrimônio, reputação, informações e vida, incluindo a prevenção de fraudes e perdas. O banco de dados analisado é de propriedade da ICTS Global (ICTS, 2010); na análise resguardamos a confidencialidade da identidade dos participantes e de suas respectivas organizações.

Os indicadores analisados estão contidos no índice de percepção moral de entendimento da visão do indivíduo frente a hipóteses de conflitos éticos. Esses indicadores estão explicados na tabela 1 e resultam de 38 questões realizadas por meio de questionários e entrevistas individuais, em ambiente organizacional, 


\section{HUMANAS}

seguindo uma escala de 1 - baixo, 2 - médio e 3 - alto potencial risco de não conformidade organizacional (compliance), conforme observamos em exemplos de questões na tabela 2. Compliance, termo anglo-saxão originário do verbo to comply, significa agir de acordo com uma regra, um pedido ou um comando. Segundo a FEBRABAN (Federação Brasileira de Bancos) compliance é o dever de cumprir, de estar em conformidade e fazer cumprir regulamentos internos e externos impostos às atividades da instituição (MORAIS, 2005).

Tabela 1

Indicadores estudados e seus significados do banco de dados AAEE.

\begin{tabular}{ccc}
\hline Indicador & Patrimonial & Enunciado \\
\hline $\begin{array}{c}\text { Potencial para } \\
\text { Suborno }\end{array}$ & Patrimonial & Grau de probabilidade de aceitar suborno em seu local de \\
trabalho \\
$\begin{array}{c}\text { Potencial para } \\
\text { Presentes }\end{array}$ & $\begin{array}{c}\text { Extra } \\
\text { patrimonial }\end{array}$ & $\begin{array}{c}\text { Grau de probabilidade de aceitar presentes de valor } \\
\text { considerável advindo de stakeholders }\end{array}$ \\
\hline
\end{tabular}

Fonte: Banco de Dados de Análise de Aderência à Ética (ICTS GLOBAL, 2011).

Tabela 2

Exemplos de questões dos indicadores estudados do Banco de Dados AAEE.

\begin{tabular}{cc}
\hline Indicador & Exemplos de questão \\
\hline Potencial para & O que você faria se alguém lhe oferecesse um suborno? \\
Suborno & Qual valor faria você pensar em aceitar um suborno? \\
Potencial para & Você acha que um funcionário que aceitou de presente uma mercadoria \\
Presentes & ou equipamento de um fornecedor deveria ser punido? \\
\hline
\end{tabular}

Fonte: Banco de Dados de Análise de Aderência à Ética (ICTS GLOBAL, 2011).

O elemento oportunidade já está inserido no contexto das responsabilidades, uma vez que só participam profissionais em posições de confiança na organização. Quando consideramos que o setor varejista supermercadista tem como uma de suas principais atividades a compra de produtos para revenda, $\mathrm{o}$ risco de oportunidade de fraude aumentaria significativamente, gerando maior vulnerabilidade potencial para os profissionais quanto a ofertas de suborno - de acordo com o relatório da Association of Certified Fraud Examiners (2010), o setor está em $4^{\circ}$ lugar do ranking em freqüência de fraude, $6,6 \%$.

Objetivando maior associação com a teoria da escala da fraude exposta neste artigo, consideramos que as respostas classificadas como baixo risco de não compliance (escala 1) são aquelas embasadas na percepção moral do indivíduo, os quais tendem agir sob princípios e não sob pressão da circunstância; 


\section{Percepção moral dos profissionais de supermercados no Brasil R.A. dos Santos, A.J. de H. Guevara \& M.C.S. Amorim}

denominaremos esse indicador como "princípios". As respostas graduadas como médio (escala 2) e/ou alto (escala 3) risco de não compliance são classificadas como "situacional", pois diante de dilemas éticos, os profissionais denotaram em suas respostas que suas ações estarão vinculadas às necessidades ou à pressão situacional que estiver exposto. Associando aos conceitos de suborno, distinguimos os seus tipos em "patrimonial", contemplado no primeiro indicador e "extra-patrimonial" no indicador "presentes".

\section{Etapa 1}

A primeira etapa da pesquisa analisa amostra não probabilística por conveniência, realizada entre os anos de 2004 e 2011, com funcionários e candidatos de 93 empresas privadas situadas no Brasil. Realizando o teste de normalidade de Anderson-Darling, considerando nível de confiança de 95\%, margem de erro de $1,25 \%$ para mais ou menos e trabalhando com uma proporção de 0,005 , uma vez que a verdadeira proporção (p) é desconhecida, o número final de indivíduos pesquisados totalizou 11.850. O software estatístico utilizado para realização de tais análises foi o MINITAB 2006.

A demografia dos pesquisados está concentrada no segmento varejista (48,7\%), sendo que nessa amostra todas as organizações pesquisadas são do ramo supermercadista. Os participantes estão concentrados na faixa salarial entre R \$1.001 a R \$7.000, (59\%). A maioria dos respondentes são funcionários $(54,7 \%)$. A maioria $(70 \%)$ dos respondentes é do sexo masculino, todos são maiores de 18 anos de idade, quase metade (46,5\%) possui entre 25 e 34 anos de idade; $56,6 \%$ são graduados (escolaridade de $3^{\circ}$ grau completo e/ou pósgraduação). A grande concentração dos participantes está na região sudeste do país $(64,6 \%)$. Há grande concentração de respondentes com nível de decisão estratégica e tática (totalizando 58,8\%).

Nesta etapa da pesquisa propomos quantificar a tendência das decisões éticas dos profissionais quando recebem uma proposta de suborno, seja ele extra ou patrimonial. Ainda, apresentamos uma análise comparativa entre os segmentos de mercado objetivando explorar qual setor possui maior sensibilidade ao tema suborno quando os profissionais são expostos a dilemas éticos.

\section{Etapa 2}

Nesta etapa apresentamos os dados no setor varejista, cuja representatividade na amostra é N=5769,48,7\%; o teste de normalidade de Anderson-Darling, considerando nível de confiança de $95 \%$, indica margem de erro de $2,42 \%$, 
para mais ou menos e proporção de 0,005 , uma vez que a verdadeira proporção (p) é desconhecida. Com o objetivo de agregar análise dirigida no segmento varejista, exploramos as grandes áreas pesquisadas, nas quais categorizamos na tabela 3, primeiro em áreas/ departamentos e, em suas atividades genéricas.

\section{Tabela 3}

Grandes áreas do segmento varejista e suas atividades genéricas.

\begin{tabular}{lccc}
\hline Área & Distribuição & Atividade & Dis tribuição \\
\hline Direcão executiva & $1,4 \%$ & & \\
Administrativo & $4,8 \%$ & & \\
Auditoria/Compliance & $1,6 \%$ & & \\
Financeiro & $5,6 \%$ & SUPORTE & $26,8 \%$ \\
Jurídico & $0,8 \%$ & & \\
RH & $3,0 \%$ & & \\
Segurança/Prev. perdas & $5,5 \%$ & & \\
Tecnologia da informação & $4,1 \%$ & & \\
\hline Logistíca & $2,2 \%$ & & \\
Marketing & $4,3 \%$ & TÉCNICA & \\
P\&D/Consultoria & $1,2 \%$ & & $32,3 \%$ \\
Engenharia & $1,3 \%$ & & $31,9 \%$ \\
\hline OPERAÇÕES & & & \\
\hline Comercial & $26,9 \%$ & COMPRAS & \\
Compras & $5,0 \%$ & & \\
\hline
\end{tabular}

Fonte: Banco de Dados de Análise de Aderência à Ética (ICTS GLOBAL, 2011).

\section{Análise e discussão dos resultados}

Etapa 1 - Análise dos indicadores e comparação entre os segmentos

Análise dos indicadores

Na figura 1, um terço dos pesquisados (34\%) aceitaria suborno patrimonial nas relações profissionais, dependendo da situação ou mesmo do impacto que o ato cause para a negociação. Pouco menos de um terço dos pesquisados (30\%) assume que receberia presentes de valor relevante (suborno extra patrimonial) de fornecedores ou prestadores de serviços, 


\section{Percepção moral dos profissionais de supermercados no Brasil}

analisando para isso as possíveis conseqüências do ato e necessidade pessoais. Podemos visualizar a disposição dos indicadores e verificar significativo nível de similaridade entre eles, a análise de correlação pode ser ponto de reflexão para estudos futuros.

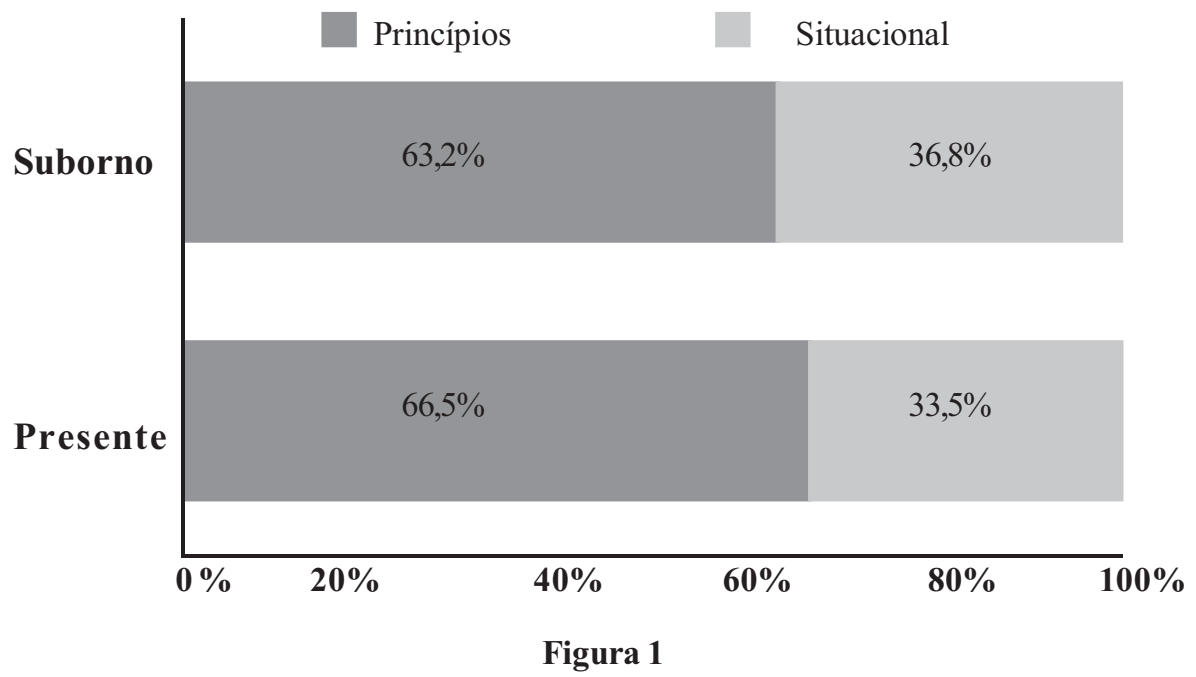

Gráfico dos indicadores frente a decisões éticas.

\section{Análise comparativa entre os segmentos}

Com o objetivo de analisar as percepções morais dos profissionais do segmento varejista quanto ao recebimento de suborno e presentes, comparamos com as percepções de profissionais dos outros segmentos de forma compilada, assim os denominamos como "demais".

Na tabela 4, conforme o modelo ANOVA, notamos que não há diferenças significativas entre as percepções dos profissionais do varejo com os demais, considerando os valores $\mathrm{P}=0.002$ para o indicador "suborno" e $\mathrm{P}=0.000$ para "presentes".

\section{Tabela 4}

ANOVA dos indicadores "suborno" e "presentes" comparando o segmento varejista com os demais.

\begin{tabular}{cccccc}
\hline & Quantidade & \multicolumn{2}{c}{ Suborno } & \multicolumn{2}{c}{ Presentes } \\
& & Média & $\begin{array}{c}\text { Desvio } \\
\text { Padrão }\end{array}$ & Média & $\begin{array}{c}\text { Desvio } \\
\text { Padrão }\end{array}$ \\
\hline Varejo & 5769 & 1,3895 & 0,5511 & 1,3489 & 0,559 \\
Demais & 6081 & 1,4211 & 0,5733 & 1,4226 & 0,6029 \\
\hline
\end{tabular}


A média sendo significativa no nível 10\%, indica que aqueles profissionais (varejo) tendem a agir mais sob princípios que os demais frente a dilemas éticos envolvendo oferta de suborno patrimonial e extra patrimonial (Figura 2).

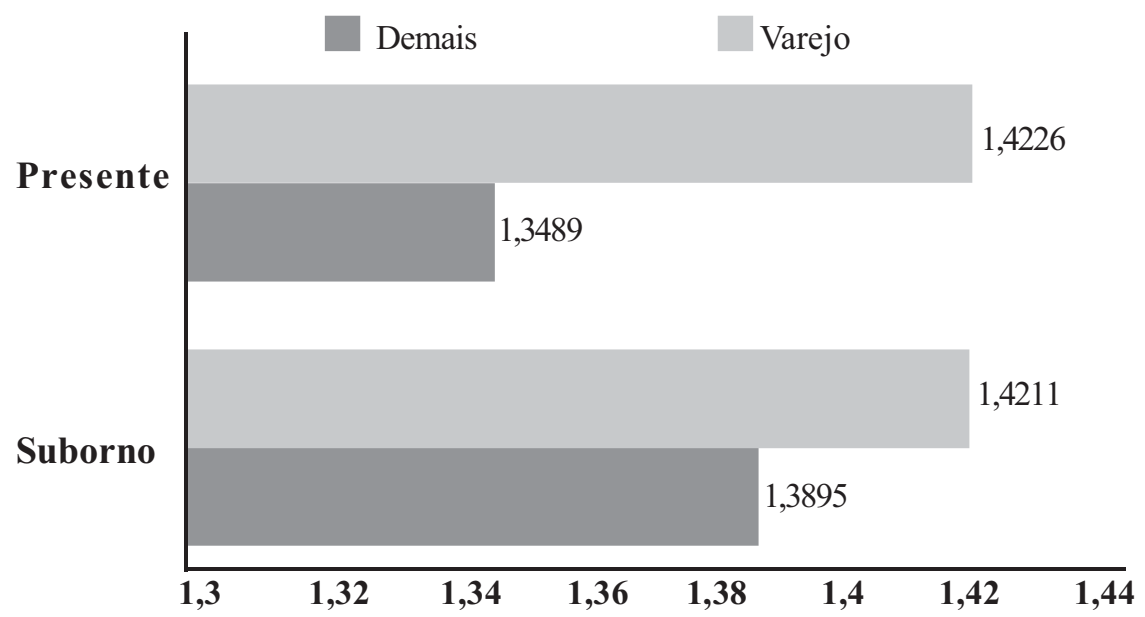

Figura 2

Gráfico dos indicadores "suborno" e "presentes" comparando o segmento varejista com os demais.

Etapa 2 - Análise dos indicadores comparando com as grandes áreas do varejo

Analisando o indicador suborno patrimonial, utilizando o modelo ANOVA (tabela 5), com intervalo de 95\%, observasse que há diferença significativa entre as diversas áreas do setor varejista, uma vez que o valor $\mathrm{p}=$ 0.003. O mesmo não ocorre com o indicador presente, uma vez que não há diferença significativa entre as áreas $(p$ value $=0.970)$, mas ainda é possível identificar uma maior similaridade em relação às áreas de suporte e compras, conforme pode ser observado na figura 3. Ainda analisando essa figura, as áreas de operações possuem maior flexibilidade quanto ao suborno patrimonial, mas por outro lado, menor quando este é extra-patrimonial. Tais observações poderão ser melhor analisadas e interpretadas em estudos posteriores. 
Percepção moral dos profissionais de supermercados no Brasil R.A. dos Santos, A.J. de H. Guevara \& M.C.S. Amorim

Tabela 5

ANOVA dos indicadores "suborno" e "presentes" comparando as atividades genéricas do segmento varejista.

\begin{tabular}{cccccc}
\hline & Quantidade & \multicolumn{2}{c}{ Suborno } & \multicolumn{2}{c}{ Presentes } \\
& & Média & Desvio & Média & Desvio \\
& & & Padrão & & Padrão \\
\hline Suporte & 1643 & 1,3664 & 0,5370 & 1,3518 & 0,5599 \\
Técnica & 451 & 1,3725 & 0,5526 & 1,3548 & 0,5681 \\
Operações & 1859 & 14239 & 0,5720 & 1,3523 & 0,555 \\
Compras & 1508 & 1,3634 & 0,5347 & 1,3442 & 0,5669 \\
\hline
\end{tabular}

\section{Suporte}

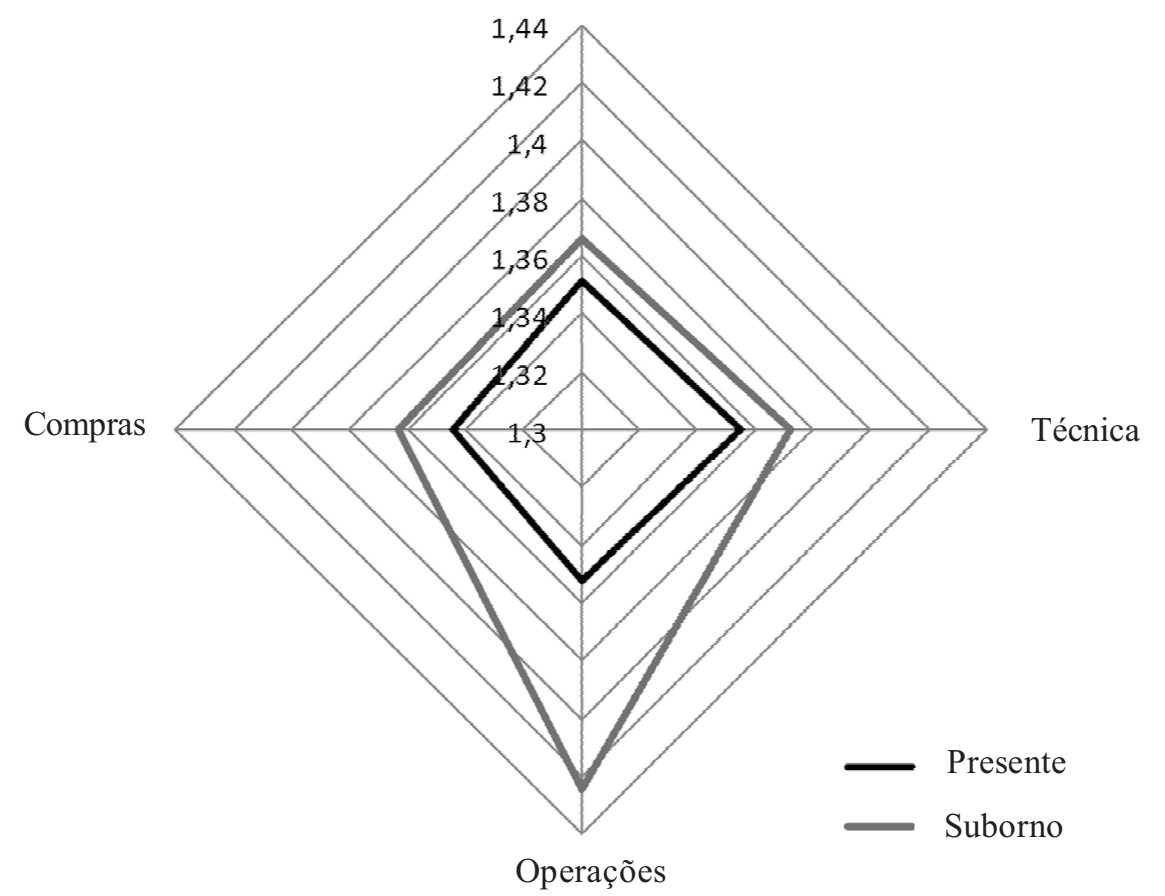

Figura 3

Gráfico comparativo dos indicadores com as atividades genéricas.

\section{Considerações finais}

Definir e mensurar fenômenos sistêmicos como fraude e corrupção é uma tarefa complexa, fato que, por sua vez, dificulta legitimar e implantar o combate e prevenção nas organizações - por motivos alheios a presente discussão, gestores sentem-se mais seguros quando diante de dados quantitativos. 
Estudos que se proponham a mensurar os custos reais e potenciais da corrupção e fraude são importantes e necessários por facilitar o debate e a intervenção. Pelo mesmo motivo, compreender as particularidades dos setores econômicos ajuda a pensar ações mitigadoras de corrupção e fraude.

Os profissionais do setor varejista de supermercados selecionados em nossa amostra têm renda entre $\mathrm{R} \$ 1.000,00$ e $\mathrm{R} \$ 7.000,00$ (66,3\%) e instrução superior $(43,5 \%)$, são homens $(69,2 \%)$ e jovens $(48 \%$,). De acordo com a literatura, jovens profissionais têm maior potencial para ceder ao suborno, enquanto que o nível de instrução amplia a percepção do dilema ético das escolhas (SANTOS. HOYOS. AMORIM, 2010). Se formação moral individual e circunstâncias agem para provocar ou segurar corrupção e fraude, a percepção do dilema ético é condição para combater e prevenir tais problemas. As ações de compliance podem atuar nesse ponto, ajudando as pessoas a reconhecer dilemas éticos e reduzindo-lhes a exposição, no trabalho, a situações potencialmente provocadoras de fraudes.

Quando comparado com os demais setores, o varejo supermercadista apresenta diferenças significativas com os demais, os profissionais do primeiro tendem a agir mais sob princípios quando a situação envolve oferta de suborno patrimonial, bem como a sua percepção da natureza moral quando da oferta de presentes, ou, de benefícios extra patrimoniais é mais reforçada. Pode-se inferir que esta percepção é mais reforçada pela organização deste ramo por sua grande exposição a este tipo de prática? Esta inquirição é influenciada pela análise comparativa entre as grandes áreas, uma vez que profissionais da área de Compras apresentam maior inflexibilidade em sua percepção moral quanto a suborno do que os demais.

Quanto às causas da menor percepção do risco moral no aceite de suborno, pesquisas qualitativas poderiam avançar na compreensão. Recorrendo apenas à literatura examinada, ressaltamos a importância das organizações em comunicar com clareza os limites permitidos para recebimento de benefícios associados ao capital social e simbólico dos indivíduos. Se a reflexão ordenada promovida pelos meios científicos não oferece consenso sobre o que é suborno, não devemos esperar que jovens profissionais saibam reconhecer os dilemas éticos, reconhecer quando não aceitar "presentes".

Por fim, as condutas individuais desenvolvem-se em condições sócio-econômicas que podem ser propícias ou não à corrupção. Esse é um campo para futuras pesquisas, com vasta literatura baseada na filosofia, sociologia e política.

\section{Referências bibliográficas}

ABRAMO, C.W. Percepções pantanosas. A dificuldade de medir a corrupção. Novos Estud. - CEBRAP, 73, Novembro de 2005. 


\section{Percepção moral dos profissionais de supermercados no Brasil \\ R.A. dos Santos, A.J. de H. Guevara \& M.C.S. Amorim}

ALBRECHT, W.S.; HOWE, K.R. \& ROMNEY, M.B. Detering fraud: the internal auditors perspective. The Institute of Internal Auditors Research Foundation, Altamonte Springs, FL, 1984.

ARRUDA, M.C.C. de; WHITAKER, M. do C. \& RAMOS, J.M.R. Fundamentos de ética empresarial e econômica. Editora Atlas, 2001.

ACFE (ASSOCIATION OF CERTIFIED FRAUD EXAMINERS). Fraud examiners manual. (http://butest.acfe.com/rttn/rttn-2010.pdf, acesso em Junho/2010).

BABBIE, E. Métodos de pesquisa de survey. Belo Horizonte: Editora da UFMG, 2003.

BORINI, F.M. \& GRISI, F.C. A corrupção no ambiente de negócios: survey com as micro e pequenas empresas da cidade de São Paulo. Rev. Adm., 44(2): 102-17, 2009.

BOURDIEU, P. A distinção: crítica social do julgamento. São Paulo e Porto Alegre: Edusp e Editora Zouk, 2007.

BREI, Z.A. Corrupção: dificuldades para definição e para um consenso. RAP, 30(1): 64-77, 1996.

CGU - Controladoria-geral da União - Instituto Ethos de Empresas e Responsabilidade Social e Grupo de Trabalho do Pacto Empresarial pela Integridade Contra a Corrupção. A responsabilidade social das empresas no combate à corrupção, 2009

COLLIS, J. \& HUSSEY, R. Pesquisa em administração. Porto Alegre: Bookman, 2005.

COSTA, A.P. \& WOOD JR, T. Fraudes corporativas. RAE, São Paulo, 52(4): 464-72, 2012.

CRESSEY, D.R. Other people's money: a study in the social psychology of embezzlement. Glencoe, Illinois: The Free Press, 1953.

DAMÁSIO DE JESUS. A corrupção no setor privado (reflexões a partir do ordenamento espanhol à luz do direito comparado). (www.damasio.com.br, acesso em Abril/2010).

DURKHEIM, É. Ética e sociologia da moral. São Paulo: Landy, 2003.

FIESP - Federação das Indústrias do Estado de São Paulo. Relatório Corrupção: custos econômicos e propostas de combate. (www.fiesp.com.br/competitividade/downloads, acesso em Junho/2010. 
GOMES, M.A.C. Uma contribuição à prevenção de fraudes contra as empresas. Tese de Doutoramento. Faculdade de Economia, Administração e Contabilidade. Universidade de São Paulo, 2000.

GÓMEZ PÉREZ, R. Problemas morais da existência humana. Lisboa: Editora CAS, 1983.

GRANOVETTER, M. Economic action and social structure: the problem of embeddedness. American Journal of Sociology, 91(3): 481-510, 1985.

GRANOVETTER, M. A construção social da corrupção. Política e Sociedade, 9 (Outubro), 2006.

HEIDENHEIMER. A.J. Perspectives in the perception of corruption. In: A.J. HEIDENHEIMER. Political corruption: readings in comparative analysis. p. 18-28. New York: Hold, Rinehart and Wilston, 1970.

ICTS GLOBAL (www.ictsglobal.com.br, acesso em Abril/2010).

KPMG. A Fraude no Brasil, Relatório de Pesquisa de 2009. (www.kpmg.com.br/ publicacoes/forensic/Fraudes_2009_port.pdf, acesso em Maio/2010).

MORAIS, E.J. de. Controles internos e estrutura de decisão organizacional: o caso da contadoria do Banco do Brasil. Dissertação de Mestrado da Universidade Federal Do Paraná, 2005.

ROMANO, R. Os laços do orgulho. Reflexões sobre a política e o mal. Unimontes Cientifica, 6(1), Jan/Jun, 2004.

SÁ, M.G. de. A Sociologia disposicionalista e o homem de negócios contemporâneo. Encontro de Estudos Organizacionais da ANPAD. EnEO 435, Tema 5, 2010

SANTOS, R.A.; HOYOS, A.J. \& AMORIM, M.C.S. Corrupção nas organizações privadas: Análise da percepção moral segundo gênero, idade e grau de instrução. Encontro de Estudos Organizacionais da ANPAD. EnEO 545, Tema 9, 2010.

SENNETT, R. A corrosão do caráter - conseqüências pessoais do trabalho no novo capitalismo. Rio de Janeiro: Record, 2002.

SEN, A. Sobre ética e economia. São Paulo: Cia. das Letras, 1999.

SLATER, P. Wealth addiction. New York: Dutton, 1980. 


\section{Percepção moral dos profissionais de supermercados no Brasil}

R.A. dos Santos, A.J. de H. Guevara \& M.C.S. Amorim

SPECK, B.W. Mensurando a corrupção: uma revisão de dados provenientes de pesquisas empíricas. Cadernos Adenauer 10: os custos da corrupção. São Paulo: Fundação Konrad Adenauer, 2000.

STUKART, H.L. Ética \& corrupção, os benefícios da conduta ética na vida pessoal e empresarial. Ed. Nobel. 2007.

TRANSPARÊNCIA INTERNACIONAL 2011 (http: //cpi.transparency.org/ cpi2011/results, acesso em Outubro/2012.

WELLS, J.T. Encyclopedia of fraud. Ed. Obsidian. 2002. 